\title{
Application Of Media Richness Theory To Data Collection
}

Beverly Wright, (E-mail: wrightb@ecu.edu), East Carolina University Paul H. Schwager, (E-mail: wrightb@ecu.edu), East Carolina University Naveen Donthu, (E-mail: ndonthu@gsu.edu), Georgia State University

\begin{abstract}
Researchers and practitioners are becoming more dependent on electronic means of data collection. This study utilizes media richness theory (MRT) as a means to better understand respondent performance in data collection among adults and adolescents. Examining the differences between paper and pencil, interview and electronic form methods of data collection, the results of this study indicate that matching task type to data collection method according to MRT principles produces improved levels of response distortion as expected; however, item omissions are not influenced in the manner anticipated from MRT concepts.
\end{abstract}

Keywords: media richness theory, data collection methodology, survey method, response distortion, item omission.

\section{INTRODUCTION}

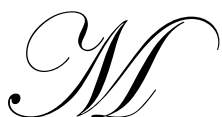

edia Richness Theory (Daft and Lengel, 1984; 1986) is a subset of Contingency Theory since it makes propositions regarding the relationship between information processing requirements and the choice and use of media (Rice, 1992). Media Richness Theory (MRT) has been applied to numerous studies to understand how different types of communication media impact the performance of various types of tasks (e.g., Daft and Lengel, 1986). Several studies from previous decades have evaluated traditional communication media to assess how different media influence task performance (e.g., Rice, 1992). More recent studies have added comparisons between traditional methods and one or more form of newer technologies (e.g., Dennis, Kinney, and Hung, 1999). The newest studies examine impacts among multiple newer forms of communication media and information transfer methods using technology, such as electronic-based mail systems and voicemail technology (e.g., Kahai and Cooper, 2003).

This study draws a parallel between the concepts of MRT and data collection methodology. Our research investigates if the choice of communication method for data collection influences respondent performance during research participation as expected according to concepts of MRT.

This topic is of particular interest since electronic data collection methods, especially Internet-based surveys, have increased in popularity among academic researchers and are perceived as able to deliver results in a cost effective and time efficient manner (McConkey, Stevens, and Loudon, 2003; Griffis, Goldsby, and Cooper, 2003). Cobanuglu, Warde, and Moreo (2001) emphasize the importance of the use of electronic communication in the field of survey methodology and stress the importance of developing deeper understanding in this area. While the future for electronically-based methodologies may offer several improvements for data collection methodology, many unknowns remain regarding this newer form of data collection (McConkey, et al, 2003). Furthermore, there is an even greater need for research studies that compare electronic data collection methods with multiple other forms of data collection (McConkey, et al, 2003). 
The use of electronic media is of interest among specific submarkets within the population. One such market is the adolescent market. Adolescents have become recognized for their increasing spending power (Clark, Martin, and Bush, 2001). Furthermore, adolescents have impressive levels of influence toward family spending (McNeal, 1992). Adult respondents are included to make comparisons among these groups.

\section{BACKGROUND}

Media Richness Theory is one of the more prominent theories to help explain the relationship between communication media and performance variables (Kinney, Watson, and El-Shinnawy, 1998). The theory was originally developed and tested using traditional media, and later expanded to include comparisons of other types of newer technologies such as voicemail or electronic mail with more traditional communication media (El-Shinnawy and Markus, 1997). More recently, media types and combinations of media types are emerging and flourishing (Negroponte, 2000). This growth has encouraged researchers to compare multiple forms of newer communication methods such as videoconferencing, electronic mail, facsimile, voicemail, and others (El-Shinnawy and Markus, 1997).

A media form's level of richness is evaluated on a continuum with the richest media on one end and the leanest media on the other end. The MRT literature places face-to-face communication as the richest communication medium and text-based forms such as memos and email as the leanest communication media (D’Ambra, et al, 1998).

MRT examines the differences in performance, such as decision quality and decision time, resulting from the use of different media (Dennis and Kinney 1998). To extend MRT concepts to data collection methodology, this research draws a parallel between decision quality and response quality. In particular, constructs to represent response quality in lieu of decision quality include measures of response distortion (Bush and Hair, 1985) and item omission (Bijmolt and Wedel, 1995; Bush and Hair, 1985).

Response distortion, which is similar to faking (Mueller-Hanson, Heggestad, and Thornton, 2003) occurs when research participants respond to survey questions in ways that are intentionally false (Bush and Hair, 1985). Item omission, omission rate or item non-response involves respondent refusal to answer particular individual questions from the complete set of questions on a survey form (Bush and Hair, 1985).

MRT suggests that the context of the task or situation is a key determinant of the influence media richness will have toward performance measures. The MRT literature provides two basic categories of task characteristics that help determine the appropriate media form to use. First, the level of uncertainty present in the task is said to influence the choice of communication media (e.g., El-Shinnawy and Markus, 1997). Uncertainty is defined as the difference between the amount of information required to perform a task and the information already possessed (Galbraith, 1973; El-Shinnawy and Markus, 1997). Second, the level of equivocality involved in the task influences media choice (El-Shinnawy and Markus, 1997). Equivocality refers to ambiguity (Daft, et al, 1987) of a situation with multiple and sometimes conflicting interpretations (Weick 1979; Daft and MacIntosh 1981). In equivocal situations, clear answers are frequently unavailable (March and Olsen, 1976). When a given task has a high level of equivocality, richer communication media produce improved response quality (D'Ambra, Rice and O'Connor, 1998).

MRT states that lean, text-based communication media are better suited for non-equivocal tasks (Daft and Lengel, 1984). Furthermore, text-based communication is also more appropriate and more preferred for communication involving numerical information (El-Shinnawy and Markus, 1997). El-Shinnawy and Markus (1997) found that users prefer text-based communication media when the need to process numerically based information is present in the situation (El-Shinnawy and Markus, 1997). 
This study places respondents in a situation and evaluates the influence of the survey task toward respondents' ability to answer questions in a quality manner. The lean, text-based media forms include paper and pencil questionnaires and electronic form (using a laptop) questionnaires. The rich media form used for this research is the in-person interview method.

\section{HYPOTHESES}

D'Ambra, Rice and O'Connor (1998) found that written text-based methods tested are perceived to have approximately equivalent levels of media richness (D'Ambra, et al, 1998). This research extends the premise that text-base methods are appropriately combined and perceived similarly among both adult and adolescent respondents participating in research studies. Therefore, we hypothesize the following:

H1a: Response quality measures will be approximately equivalent among text-based data collection methods for adolescent respondents.

H1b: Response quality measures will be approximately equivalent among text-based data collection methods for adult respondents.

Since MRT (Daft and Lengel, 1984, 1986) states that matching a communication format to a task improves performance, we apply these concepts to data collection methodology and hypothesize that lean data collection formats will produce improved survey performance factors when the survey task is non-equivocal in nature and numerically based. Since the response quality factors include response distortion and item omission, an improvement in response quality would equate to a decrease in response distortion and a decrease in item omissions. Therefore, the following hypotheses are given:

H2a: Text-based data collection methodologies (paper and pencil questionnaires and electronic forms) will produce lower levels of response distortion for non-equivocal survey tasks involving numerical information among adolescent respondents.

H2b: Text-based data collection methodologies (paper and pencil questionnaires and electronic forms) will produce lower levels of response distortion for non-equivocal survey tasks involving numerical information among adult respondents.

H3a: Text-based data collection methodologies (paper and pencil questionnaires and electronic forms) will produce lower levels of item omissions for non-equivocal survey tasks involving numerical information among adolescent respondents.

H3b: Text-based data collection methodologies (paper and pencil questionnaires and electronic forms) will produce lower levels of item omissions for non-equivocal survey tasks involving numerical information among adult respondents.

\section{RESEARCH METHOD}

A survey was conducted among college aged males and adolescent males involved in scouting. The survey task involves exposing all respondents to equivocal and non-equivocal survey tasks. Furthermore, all respondents were asked to provide a numerical response for both an equivocal and a non-equivocal task as well as a nonnumerical response for both equivocal and non-equivocal tasks. Data quality was evaluated using t-tests to reveal significant differences in responses to each of the four types of questions. A total of 436 adolescents and adults participated in the study. Responses by data collection methodology include 197 responses for the paper and pencil version, 90 responses for the interview version and 149 responses for the electronic form version. Furthermore, adolescents accounted for 158 responses while adults accounted for 278 of the respondents. 


\section{ANALYSIS AND RESULTS}

T-tests were used to examine differences between text-based formats among the adolescent and adult samples. Additionally, t-tests for proportions were used to determine if there were significant differences in response distortion and item omissions between the text-based data collection methodologies and the interview methodology.

Data quality measures of response distortion and item omissions were compared across both text-based methods of electronic form and questionnaire. As hypothesized, data quality among text-based communication methods were perceived equivalently with the exception of response distortion among adolescents where electronic form respondents produced significantly higher levels of distortion when compared to their hardcopy questionnaire counterparts $(\mathrm{t}=2.38, \mathrm{p}<.05)$. Therefore, $\mathrm{H} 1$ is supported. The unexpected finding of response distortion level differences only among the adolescent sample may be partly due to perceptions of novelty associated with laptop computer usage among adolescents.

As expected, the text-based paper and pencil methodology had the lowest proportion of distortion with this non-equivocal task that involved listing numerical years of video game play. However, the difference in the proportions of distorted answers between paper and pencil and interview respondents was significant at the .10 level $(\mathrm{t}=1.82)$. Furthermore, the difference between electronic form and interview respondents was insignificant. Hence, the form of data collection as text versus non-text does not appear to have a strong influence on the levels of distortion for non-equivocal tasks involving numerical information. Thus, results provide partial support for $\mathrm{H} 2$.

The difference in distortion for a non-equivocal task between text-based forms of paper and pencil and electronic form compared to levels of distortion among richer forms of data collection methodology, such as the interview method, were not as strong as anticipated. While there is a significant difference at the .10 level between paper and pencil and interview methodologies, there is not a significant difference in distortion between the other text-based methodology, electronic form, and interview. Perhaps the electronic form was a little more difficult to view compared to a tangible questionnaire, which may have resulted in respondents erroneously providing distorted answers more so for the electronic form.

Text-based forms were hypothesized to yield lower levels of item omission for non-equivocal questions involving numerical information and involving a sensitive question. T-tests were employed to assess differences in the proportion of non-response among the three data collection methodologies. Findings reveal that there are no significant differences among all three data collection methodologies for this question. Text-based forms appear to produce a similar proportion of non-response ( $\mathrm{t}=.92$ adolescents; $\mathrm{t}=1.4$ adults) compared to richer data collection methods, such as the interview method used here. Therefore, there is no support for H3.

\section{IMPLICATIONS AND CONCLUSIONS}

Concepts from MRT partially transfer to the field of data collection methodology for adolescent respondents. These findings suggest that the use of text-based data collection methods produce similar data quality among adult respondents. However, when conducting research among adolescent respondents, the use of text-based data collection methods which use technology (i.e., email, laptop computers, etc), may not produce equivalent levels of data quality when compared to other text-based format such as paper and pencil. Thus, the use of mixed mode surveying among adolescents may have more of an influence toward data quality measures.

Other concepts of MRT, such as the matching of equivocal or non-equivocal tasks to appropriate media, did not transfer quite as clearly as expected. One difficulty with the transfer might be that the categorization of textbased methods such as paper and pencil questionnaires and electronic forms do not appear to produce similar results with respect to survey factors. Perhaps there is still a fairly high level of novelty for using laptops to participate in a 
survey, particularly among adolescents. This novelty may set electronic forms apart from other text-based methods such as traditional paper and pencil means for collecting data.

Non-equivocal, numerically-based questions were best answered (lowest levels of distortion and item omission) by implementing a self-administered visually simple methodology of paper and pencil questionnaire. The more technical but still text-based method involving an electronic means of data collection did not produce the anticipated results for distortion. Also, text-based forms did not appear to hold together well for this research audience, perhaps partially due to the observed novelty of computer use among these younger research participants.

The following suggestions are given based on these findings for both academic and managerial researchers:

- When practical, implement a paper and pencil survey methodology over the use of an electronic form for surveying adolescents.

- $\quad$ Manage results from different text-based methods separately for adolescents since levels of data quality may vary for this research audience.

- $\quad$ Expect similar levels of data quality for various text-based methods when surveying adults.

- Weigh the practical advantages and disadvantages of using the interview method against other methods since improvements to data quality may not occur under certain situations.

This is the first known study to apply the concepts of MRT to the field of data collection methodology. The concepts of Media Richness Theory provided some of the anticipated results among the adolescent consumers; however, some results were unexpected. Both response quality measures produced similar results among the adult sample; however, one response quality measure (response distortion) produced results that were not equivalent between the two text-based methods of data collection; however, this finding was only relevant among the adolescent sample.

\section{LIMITATIONS}

The samples chosen could have been more representative of the population of potential research respondents for adolescents and adults. For example, adolescents included Boy Scouts troops from a southeastern region. Inclusion of other adolescent groups may have provided a more representative sample of adolescents. Additionally, adult respondents included college business students at a southeastern university. Inclusion of a broader spectrum of adults would have improved the generalizability of the findings.

Only non-equivocal tasks with numerical information are included in this study to apply the concepts of MRT to the data collection field. This study could be further enriched with the addition of other dimensions, such as equivocal tasks and the matching to the appropriate media. Furthermore, including of additional data collection methodologies would provide a more comprehensive perspective of the applicability of MRT to data collection methods.

\section{REFERENCES}

1. Bijmolt, T. H. A. and Wedel, M. (1995). The effects of alternative methods of collecting similarity data for multidimensional scaling. International Journal of Research in Marketing, 23, 363-371.

2. Bush, A.J. and Hair, J.F. (1985). An assessment of the mall intercept as a data collection method. Journal of Marketing Research, 22(2), 158-167.

3. Clark, P.W., Martin, C.A., and Bush, A.J. (2001). The effect of role model influence on adolescents' materialism and marketplace knowledge. Journal of Marketing Theory and Practice, 9(4), 27-36.

4. Cobanoglu, C., Warde, B. and Moreo, P. J. (2001). A comparison of mail, fax and web-based survey methods. International Journal of Market Research, 43(4), 441-452. 
5. Daft, R. L. and Lengel, R. H. (1984). Information richness: A new approach to managerial behavior and organizational design. Research in Organizational Behavior, 6, 199-233.

6. Daft, R. L. and Lengel, R. H. (1986). Organizational information requirements, media richness and structural design. Management Science, 32(5), 554-571.

7. Daft, R. L., Lengel, R. H. and Trevino, L. K. (1987). Message equivocality, media selection and manager performance. MIS Quarterly, 11(3), 354-366.

8. Daft, R. L. and MacIntosh, N. B. (1981). A tentative exploration into the amount and equivocality of information processing in organizational work units. Administrative Science Quarterly, 26(2), 207-224.

9. D’Ambra, J., Rice, R. E. and O’Connor, M. (1998). Computer-mediated communication and media preference: An investigation of the dimensionality of perceived task equivocality and media richness. Behaviour and Information Technology, 17(3), 164-174.

10. Dennis, A. R. and Kinney, S. T. (1998). Testing media richness theory in the new media: The effects of cues, feedback, and task equivocality. Information Systems Research, 9(3), 256-285.

11. Dennis, A. R., Kinney, S. T. and Hung, Y. C. (1999). Gender differences in the effects of media richness. Small Group Research, 30(4), 405-437.

12. El-Shinnawy, M. and Markus, M. L. (1997). The Poverty of media richness theory: explaining people's choice of electronic mail vs. voice mail. International Journal of Human-Computer Studies, 46(4), 443467.

13. Funk J.B., Buchman D.D., and Germann J.N. (2000). Preference for violent electronic games, self-concept and gender differences in young children. American Journal of Orthopsychiatry 70, 233-241

14. Galbraith. J. (1973). Designing Complex Organizations. Boston, MA: Addison-Wesley Longman Publishing Co., Inc.

15. Griffis, S. E., Goldsby, T. J., and Cooper, M. (2003). Web-based and mail surveys: A comparison of response, data and cost. Journal of Business Logistics, 24(2), 237-258.

16. Kahai, S.S., and Cooper, R.B. (2003). Exploring the core concepts of media richness theory: The impact of cue multiplicity and feedback immediacy on decision quality. Journal of Management Information Systems, 20(1), 263-299.

17. Kinney, S. T., Watson, R. T. and El-Shinnawy, M. (1998). The effect of media and task on dyadic communication. IEEE Transactions on Professional Communication, 41(2), 140-142.

18. March, J.G. and Olsen, J.P. (1976). Ambiguity and Choice in Organizations. Bergen: Universitetesforlaget.

19. McConkey, C. W., Stevens, R. E., and Loudon, D. L. (2003). Surveying the service sector: A pilot study of the effectiveness of mail vs. internet approaches. Services Marketing Quarterly, 25(1), 75-84.

20. McNeal, J. U. (1992). Kids as Customers: A Handbook of Marketing to Children. New York, NY: Lexington Books.

21. Mueller-Hanson, R., Heggestad, E.D., and Thornton, G.C. (2003). Faking and selection: Considering the use of personality from select-in and select-out perspectives. Journal of Applied Psychology. 88(2), 348355 .

22. Negroponte, N. (2000). From being digital to digital beings. IBM Systems Journal, 39(3/4), 417-418.

23. Rice, R. E. (1992). Task analyzability, use of new media, and effectiveness: A multi-site exploration of media richness. Organization Science, 3(4), 475-500.

24. Roedder John, D. (1999). Consumer Socialization of Children: A Retrospective Look at Twenty-Five Years of Research. The Journal of Consumer Research, 26(3), 183-213.

25. Weick, K. E. (1979). The Social Psychology of Organising. Reading, MA: Addison-Wesley.

26. Zollo, P. (1999). Wise up to teens: Insights into marketing and advertising to teenagers. Ithaca, NY: New Strategists Publications, Inc. 